\title{
Bioenergy chain building: a collective action perspective
}

\author{
Luigi Cembalo ${ }^{1 *}$, Francesco Caracciolo ${ }^{1}$, Giuseppina Migliore ${ }^{2}$, Alessia Lombardi ${ }^{1}$ and Giorgio Schifani ${ }^{2}$
}

\author{
* Correspondence: \\ cembalo@unina.it \\ ${ }^{1}$ Department of Agriculture, AgEcon \\ and Policy Group, University of \\ Naples Federico II, Via Università 96, \\ Portici, NA 80055, Italy \\ Full list of author information is \\ available at the end of the article
}

\begin{abstract}
Depletion of natural resources has become a key issue on the European policy agenda. Bottom-up measures have emerged in several countries with a view to promoting awareness campaigns and environmental sustainability, with the agenda set by individuals who start up collective initiatives at the local level. Such collective action provides an incentive to free-ride on the contribution of others. Social norms and the consequent behavior of individuals involved in collective action assume a key role in ensuring sustainable use of a public good, achieving significant, long-lasting success. The present study aims to ascertain which determinants most affect farmers' willingness to contribute to common resources. The empirical study was conducted in an area in the province of Avellino (southern Italy) most affected by soil erosion problems. The study focused on the willingness of farmers to contribute to the public good through biomass production (Giant Cane). In all, 175 face-to-face questionnaires were administered to farmers in September-November 2013. Schwartz's norm-activation model variables were collected. A Tobit model was implemented in which the dependent variable was the land farmers stated they were willing to cultivate with Giant Cane. Four on five psychological constructs, based on the NAM, proved statistically significant with the expected sign, showing that an altruistic behavioral approach is useful to predict the individual's decision to adopt cooperation norms.
\end{abstract}

Keyword: Public goods; Norm-activation model; Tobit

\section{Background}

Environmental pollution, biodiversity loss, climate change and the inexorable depletion of natural resources have become major issues on the European policy agenda. However, European governments have been very reluctant to adopt radical approaches to solve such problems (Rootes, 2012; Hisschemöller and Sioziou, 2013). In this context, bottom-up measures have emerged in several countries with a view to promoting awareness campaigns and practical action aimed at environmental sustainability (Caracciolo and Lombardi, 2012). By their very nature, such measures are set up by individuals who offer their time and resources to start up collective action initiatives at the local level. This has major implications for the theory of public goods. Indeed, no "rational selfish" individual would be willing to contribute to the production of a public good even when, in a condition of cooperation with other individuals, this contribution would entail a reciprocal benefit (Liebe et al. 2011). This assumption, known as the "zero contribution thesis", has been contradicted by some theoretical and empirical

(c) 2014 Cembalo et al.; licensee Springer. This is an Open Access article distributed under the terms of the Creative Commons Attribution License (http://creativecommons.org/licenses/by/4.0), which permits unrestricted use, distribution, and reproduction in any medium, provided the original work is properly credited. 
cases (Olson, 1965; Ostrom, 1991; Gibson et al. 2005; Ostrom, 2010; Sayfang 2010). However, the production of a public good entails the non-excludability of individuals from (direct or indirect) use of the good itself, also for individuals who do not contribute to supplying the good. This clearly provides an incentive to rely on the contribution of others and use the good as a free rider. When such a situation occurs, it is referred to as a social dilemma (Olson, 1965; Dawes et al. 1986; Ostrom, 2000). A social dilemma may be defined by a situation where each member of a group gains a better payoff if he/she pursues his/her personal interest but, at the same time, everyone benefits from the fact that all members of that group aim at a common interest.

Better and more sustainable management of common resources is achieved when the rules concerning the use of common resources are defined by involving economic subjects who are in a situation of interdependence (Ostrom, 2000; Ostrom 2010; Ostrom and Walker 2003). The social norms that arise as a result of interactions aim to reduce the problem of free-riding, since they are based on relations of reciprocity and trust (Ostrom, 2010). This assumption is a core idea in the theory of public goods and collective actions. Following this line of reasoning, social/personal norms and the consequent behavior of individuals involved in collective action assume a key role in ensuring sustainable use of such goods, achieving significant, long-lasting success. Such success is assured by the rules put in place in virtue of a reciprocal consensus within the community (Berkes, 1987). This is why, in order to achieve a collective action with high payoffs, it is necessary that individuals share social norms of cooperation. However, individuals show different willingness to start reciprocity and then collective action. More precisely, as illustrated by Ostrom (2000), collective action may be initiated thanks to the presence of conditional cooperators. Therefore, individuals "who are willing to initiate cooperative action when they estimate others will reciprocate and to repeat these actions as long as a sufficient proportion of the others involved reciprocate" (Ostrom, 2000 - p. 142). Put differently, when some individuals initiate cooperation, others learn to trust them and are more willing to adopt reciprocity themselves, leading to higher levels of cooperation. Conditional cooperators are thus the source of relatively high levels of contribution in the management of common resources. From here it emerges that social dilemma and trust in other people's cooperation represents the most important determinants that affect collective action.

Several types of collective action have relevance to natural resource management. To the best of our knowledge, scholars have restricted their studies only to long-surviving cooperation systems, like use and governance of forests (Agrawal and Goyal, 2001; Antinori and Bray, 2005; Gibson et al. 2005), irrigation systems (Meinzen-Dick et al. 2002; Fujiie et al. 2005) and food community (Migliore et al. 2014, 2015). The existence of different types of individuals allows the assumption that among economic actors some are able to contribute to the management of common resources. To understand whether conditions to generate collective action exist, dilemma concern and trust in other people's cooperation are not sufficient predictors of such behavior.

The present study aims to ascertain what determinants most affect farmers' willingness to contribute to common resources. The hypothesis underlying the study is that an altruistic behavioral approach, using psychological constructs, could be useful to predict the individual's decision in sharing cooperation norms. Cooperative behavior is more likely when economic actors are aware of the consequences and aware of the 
responsibility of their action on others, in a context featuring social dilemma and trust in other people. Among public goods, an important role may be played by biomass production in an agro-energy chain.

The empirical study was conducted in an area in the province of Avellino (southern Italy), most affected by soil erosion problems. The main crop in the area is currently wheat. The study focused on the willingness of farmers to contribute to the public good through biomass production. The biomass crop suggested was Arundo donax (Giant Reed); it was chosen because of its high biomass productive efficiency, its ability to significantly mitigate soil erosion risk (it is a multi-year crop), and for its capacity to yield an income comparable to wheat. Participants in the proposed, though hypothetical, agro-energy chain were informed of the positive environmental effects of producing the crop in question: increased production of agro-energy means a reduction in pollution emissions (Kotchen and Moore, 2007); and contributes to mitigate soil erosion risk.

About 175 face-to-face questionnaires were administered to farmers in SeptemberNovember 2013. Schwartz's norm-activation model (NAM) variables were collected (Schwartz, 1977; Schwartz and Howard, 1980). A principal component analysis was performed on NAM variables, allowing identification of five psychological constructs namely: social dilemma, awareness of responsibility, personal norms, trust in other people's cooperation and awareness of consequences. Factorial scores of the above constructs, as well as some farmers' and farm characteristics, were implemented in a Tobit model in which the dependent variable was the amount of land stated by farmers potentially involved in giant reed cultivation. Four out of five psychological constructs proved statistically significant with the expected sign, showing that an altruistic behavioral approach, by using psychological constructs, is useful to predict the individual's decision to adopt cooperation norms.

The paper is organized as follows: in section Norm activation model of pro-social behavior we review the theoretical framework for describing farmers' motivational attitudes toward participation. In section Methods we describe the data and the empirical model, while results of the econometric model are presented in section Results and discussion. Conclusions follow, including some important caveats and limitations.

\section{Norm activation model of pro-social behavior}

Environmental depletion problems present an intrinsic contradiction between the optimal choice for a rational individual and the social optimum. The trade-off between individual and collective benefit has often been conceptualized within psychological models of altruistic behavior such as Schwartz's norm-activation model (NAM) (Schwartz, 1977; Schwartz and Howard, 1980). In general terms, Schwartz argued that personal norms are the only direct determinants of pro-social behavior patterns. One important class of pro-social behavior, with broad applicability, is cooperation.

According to Schwartz, personal (or moral) norms influence behavior when actors are aware that certain actions have consequences on others' wellbeing (called awareness of consequences), accepting the responsibility of those actions (awareness of responsibility). Put differently, relationships between personal norms and cooperative behavior is moderated by the awareness of consequences (AC) and by the awareness of responsibilities (AR) of such actions on other people. The NAM proposed by Schwartz 
generated diverse approaches applied both in social (Hopper and Nielsen 1991) and in environmental contexts (Stern et al. 1999; Joireman et al. 2001; De Groot \& Steg, 2009). Among the latter, the NAM was successfully implemented in empirical studies concerning the willingness to pay for environmental protection (Liebe et al. 2010; Guagnano, 2001; Guagnano et al. 1994). In these studies, however, the relationships among NAM's key factors remain fuzzy. Some scholars find that personal norms are the best predictors of environmental behavior (Stern et al. 1999). Others indicate that awareness of consequences on the environment, in agreement with personal norms, can be the main predictors of pro-environmental behavior (Hopper and Nielsen, 1991; Vining and Ebreo, 1992). Others, again, suggest that extra factors be implemented in the NAM (Blamey, 1998; Joireman et al. 2001).

Indeed, it has been shown that social rather than personal norms are related to environmental behavior (Ebreo et al. 2003). Guagnano et al. (1995) in a study on waste recycling found that external conditions, that is, personal costs and presence or otherwise of recycling bins, affect the relationship between the key factors of the NAM and behavior. In line with these findings we believe that other factors could be implemented within the NAM. According to the literature on participation in natural resources management and collective action, the additional factors should be sought after in the concept of social capital. Importantly, there are many interpretations of social capital, but one useful definition was made by Ostrom: “...the shared knowledge, understandings, norms, roles, and expectations about patterns of interactions that groups of individuals bring to a current activity..." (Ostrom, 1999:176). In this regard, relations of trust, reciprocity and exchanges, common rules and norms are often viewed as important mechanisms for building social capital assets (Pretty and Ward, 2001).

Nevertheless, in a perspective of collective action the key question is not whether any one individual will contribute, but whether enough individuals will contribute rather than free-ride. Individuals are seen to have contingent strategies or preferences, cooperation being contingent on certain aspects of the choice-situation. For example, cooperation has been found to be more likely when it is perceived that the good will only be provided if every member of the collective action contributes. In other words, cooperation is more likely when it is perceived that collective action will have a desirable outcome. For these reasons the key determinants of willingness to contribute to the public good should include social dilemma and trust in other people's cooperation. More precisely, we assume that pro-social behavior is predicted by five types of determinants: social dilemma, trust in other people, social/personal norms, awareness of consequences and awareness of responsibility. Among these, social/personal norms are related to a "moral obligation to perform or refrain from specific actions" (Schwartz \& Howard, 1981), p. 191. The awareness of consequences is defined as whether someone is aware of the positive or negative consequences for others when acting or not acting pro-socially to protect the environment. Finally, awareness of responsibility is described as a condition in which "a person believes he or she can make a useful contribution to the solution of the problem, whith perceived outcome efficacy" (Montada, and Kals, 2000; De Groot and Steg, 2009). However, according to the literature on collective action, it is important to stress that trust in other people occurs when individuals are engaged in an interaction process. Therefore it 
is possible to suppose that in an early-stage, hypothetical, collective action this variable could be difficult to predict.

\section{Methods}

The data collected through the administration of the questionnaire with face-to-face interviews are discussed here in relation to the main questionnaire sections. The aim was to collect information to interpret and understand the choice behavior, and the psychological constructs, of 200 interviewed farmers. Farmers' socio-demographic data were also collected, as well as details on their general farm organization. Finally, farmers' most recent choices in terms of investments and innovation in their farm were collected as well as in terms of participation in formal or informal forms of cooperation or contract.

We first drafted a pilot questionnaire. A final version of the questionnaire was then organized into three main sections: first, socio-demographic; secondly, a detailed description of biomass cultivation, specifically giant reed, the set-up of the bioenergy chain in the study area, the need for collective action from the local farmers; thirdly, the set of questions related to the NAM. As for the latter, a seven-point Likert scale was used to help respondents express their level of agreement between the statements provided and their own motivations.

Administration of the face-to-face survey in the case-study area provided 200 questionnaires from the randomly selected sample. Descriptive statistics were collected on the 200 farmers in question although only 171 were used in the model due to data missing in the NAM section of the questionnaire. Based on the data collected by the first section of the questionnaire (summarized in Table 1), in our sample the entrepreneurs are mostly male (63\%), aged on average 43 , full-time farmers and owners of the land they cultivate.

The sample farms cover an area of 4092 ha, of which 3706 ha are cultivated. Farm size is quite variable in the sample, ranging from a minimum of 1.5 ha to a maximum of 340 ha. However, the most frequent size (sample mode) is 20 ha. Farms are generally

Table 1 Farmers' SDs and farm characteristics

\begin{tabular}{llllll}
\hline & Description & Mean & Std.dev & Min & Max \\
\hline Gender & 1 if male; 0 female & 0.61 & N.A. & 0 & 1 \\
Age & & 43.17 & 11.76 & 18 & 80 \\
Farm size & Total area of sample farms (ha) & 20.46 & 26.66 & 1.5 & 340 \\
Total cultivated area & Total cultivated area of sample farms (ha) & 18.59 & 23.52 & 1 & 300 \\
Full-time farmer & 1 if full-time; 0 otherwise & 0.77 & N.A. & 0 & 1 \\
Individual farmers & 1 if individual; 0 otherwise & 0.96 & N.A. & 0 & 1 \\
Number of plots & & 6 & & 1 & 30 \\
Land ownership & & & & & \\
& & & & & 0 \\
& Property & 0.72 & N.A. & 0 & 1 \\
& Rent & 0.26 & N.A. & 0 & 1 \\
& Other & 0.02 & N.A. & 0 & 1 \\
Crops & Arable crops & & & & \\
& Fruit trees & 16.70 & 21.91 & 0.5 & 280 \\
& & 0.5955 & 1.14 & 0 & 9 \\
\hline
\end{tabular}

N.A: not applicable. 
fragmented into several plots, varying from a minimum of 1 up to 30 plots, with an average number of six per farm. Arable crops are clearly predominant in the sample farms (93\% of the total cultivated land). Only a very small share of the land is left for olive trees, industrial crops and grapevines.

Erosion and landslides, along with steep slopes, are the most important causes of land abandonment in the sample farms. Indeed, for the above reasons in 60 farms plots accounting for 178 ha are no longer cultivated.

Entrepreneurs' attitudes to change and openness to innovation were explored by investigating the investments and innovations introduced into their farms in the last five years, as summarized in Table 2. In all, 70\% of entrepreneurs had invested in new equipment or new processing systems or had bought more land during the past five years. Considerably fewer (46\%) had introduced some innovation in cropping systems, techniques and farm organization.

Not surprisingly, the younger entrepreneurs are more open to new investments and innovations: the mean age of the "innovators" (41) is lower than the mean age of the whole sample (43) and the most frequent value (mode) is 38 . Cooperation and collective contracts are not particularly common in the sample. Although more than half of the sample (56\%) are aware of the presence of some forms of farmer cooperation and contracts in the area, only $32 \%$ of the sample entrepreneurs have participated, focusing mainly on the marketing side to control uncertainty, to secure a minimum price and access to markets (Table 3).

Farmers who participate in different forms of cooperation are generally younger (40 years old) than the sample average (43), and farm size is larger (25.58 ha) than the average size of the sample (20.46 ha). The most common form of contract they are involved with $(68 \%)$ is informal and one-year long.

The last section of the questionnaire served to collect NAM (or psychological constructs) variables. In Table 4 the full statements presented to collect NAM variables and some descriptive statistics are reported.

A crucial aspect in the analysis regards the elicitation of the key response variable of interest: an open-ended question was used to elicit farmers' intentions to participate in the bioenergy supply chain. The latter was measured by means of the stated intention

Table 2 Investments and innovation in the past five years*

\begin{tabular}{lll}
\hline & Absolute freq. & Relative freq. \\
\hline Investments in the last 5 years: & 139 & 0.70 \\
Machines & 119 & 0.60 \\
New constructions & 66 & 0.33 \\
Processing and packaging & 6 & 0.03 \\
Marketing & 11 & 0.06 \\
Land acquisition & 83 & 0.42 \\
Other & 1 & 0.01 \\
Innovations in the last 5 years: & 91 & 0.46 \\
Cropping system changes & 35 & 0.18 \\
Cropping technique changes & 9 & 0.05 \\
Organization changes & 64 & 0.32 \\
\hline
\end{tabular}

*The number of investments and innovations is greater than the number of farms as some farms have adopted more than one. 
Table 3 Presence of forms of cooperation in the area and participation

\begin{tabular}{lll}
\hline & Absolute freq. & Relative freq. \\
\hline Forms of cooperation in the area: & 111 & 0.56 \\
Informal contracts & 66 & 0.33 \\
Cooperatives and trademarks & 40 & 0.20 \\
Supply chain contracts and guaranteed minimum price & 2 & 0.01 \\
Participation in cooperation activities: & 64 & 0.32 \\
Cooperation on the production side* & 16 & 0.08 \\
Cooperation on the marketing side** & 48 & 0.24 \\
\hline
\end{tabular}

*Technical assistance, supply of production inputs and raw materials, transfer of technological innovations.

**Product marketing, minimum price guarantee, less uncertainty in product allocation, access to markets.

of farmers to allocate a share of their land (measured in hectares) for cultivating giant reed $(\mathrm{AB})$. This response could be assumed as a linear, additive and separable function of the $h$-farmer's observed individual attributes $\left(\mathrm{IA}_{h}\right)$, of the structural characteristics $\left(\mathrm{FC}_{\mathrm{h}}\right)$ of the farms owned, and of the $h$-farmer's psychological constructs, or NAM variables $\left(\mathrm{PC}_{\mathrm{h}}\right)$. Our research focused on identifying which of the above factors may

Table 4 Statements to collect NAM (psychological constructs) variables and the main descriptive statistics - (Obs. 171)

\begin{tabular}{|c|c|c|c|c|c|}
\hline Statement & $\begin{array}{l}\text { Variable } \\
\text { code }\end{array}$ & Mean & St.dev & Min & Max \\
\hline \multicolumn{6}{|l|}{ Social Dilemma (-) } \\
\hline $\begin{array}{l}\text { If individually I do something for the environment it will not } \\
\text { change anything }\end{array}$ & NAM1 & 3.15 & 2.231 & 1 & 7 \\
\hline $\begin{array}{l}\text { If other local farmers do not participate in biomass agroenergy, } \\
\text { I will not be willing to contribute to this supply chain either. }\end{array}$ & NAM2 & 2.64 & 1.927 & 1 & 7 \\
\hline $\begin{array}{l}\text { If I do something for the environment, I am ingenuous, because I will } \\
\text { always suffer the environmental consequences of damaging action } \\
\text { committed by others }\end{array}$ & NAM3 & 2.72 & 1.959 & 1 & 7 \\
\hline \multicolumn{6}{|l|}{ Awareness of responsibility (+) } \\
\hline $\begin{array}{l}\text { I see myself as a possible activist in the production of biomass } \\
\text { (Arundo donax) }\end{array}$ & NAM4 & 4.56 & 1.610 & 1 & 7 \\
\hline $\begin{array}{l}\text { I would like, in the future, to contribute actively to the production of } \\
\text { energy from renewable and more environmentally sustainable resources. }\end{array}$ & NAM5 & 5.99 & 1.156 & 1 & 7 \\
\hline $\begin{array}{l}\text { In the coming weeks I will improve my knowledge concerning the } \\
\text { possibility of cultivating Arundo donax for biomass production }\end{array}$ & NAM6 & 5.29 & 1.348 & 1 & 7 \\
\hline \multicolumn{6}{|l|}{ Personal/social norms (+) } \\
\hline $\begin{array}{l}\text { Participating in a collective action for producing biomass is for } \\
\text { me important in order to contribute to helping the environment }\end{array}$ & NAM7 & 6.11 & 1.119 & 1 & 7 \\
\hline $\begin{array}{l}\text { Contributing to the stewardship of the environment is a moral } \\
\text { obligation }\end{array}$ & NAM8 & 5.85 & 1.427 & 1 & 7 \\
\hline \multicolumn{6}{|l|}{ Trust in other people's cooperation (-) } \\
\hline $\begin{array}{l}\text { I believe also other farmers in my area would be willing to start } \\
\text { collective action for the production of biomass, obtaining clean } \\
\text { energy and helping the environment }\end{array}$ & NAM9 & 5.08 & 1.493 & 1 & 7 \\
\hline $\begin{array}{l}\text { My family and friends would be proud if I contributed to the production } \\
\text { of energy from renewable resources through biomass production }\end{array}$ & NAM10 & 5.44 & 1.406 & 1 & 7 \\
\hline \multicolumn{6}{|l|}{ Awareness of consequences ( + ) } \\
\hline The best way to solve environmental issues is to act collectively & NAM11 & 6.68 & 0.795 & 1 & 7 \\
\hline $\begin{array}{l}\text { Improvement in environmental conditions can only be achieved } \\
\text { through collective action }\end{array}$ & NAM12 & 6.01 & 1.581 & 1 & 7 \\
\hline
\end{tabular}

Expected signs in parentheses. 
affect and explain at least part of the variation in the key response variable $\left(A B_{h}\right)$. Analytically,

$$
\mathrm{AB}_{\mathrm{h}}=\alpha+\beta \mathrm{IA}_{\mathrm{h}}+\gamma \mathrm{FC}_{\mathrm{h}}+\delta \mathrm{PC}_{\mathrm{h}}+\varepsilon_{\mathrm{h}}
$$

where $\beta, \gamma$ and $\delta$ are the parameter vectors to be estimated in order to assess respectively the role of individual farmers' attributes $\left(\mathrm{IA}_{\mathrm{h}}\right)$, farm structural characteristics $\left(\mathrm{FC}_{\mathrm{h}}\right)$, and farmers' psychological constructs $\left(\mathrm{PC}_{\mathrm{h}}\right) . \varepsilon_{\mathrm{h}} \sim \mathrm{N}\left(0, \sigma^{2}\right)$ are the error terms, while $\alpha$ is the intercept. Figure 1 shows the frequency distribution of farmers' stated intention to crop giant reed, with a 0 hectare response expressed by about $8 \%$ of the respondents. Since null intention expressed by farmers assumes the typical corner-solution value of zero, the empirical model employed has to consider the presence of a censored outcome.

Ordinary Least Square (OLS) regression does not yield consistent parameter estimates due to a censored sample that is not representative of the population. In the Tobit model the regression is specified as an unobserved latent variable, $A B^{*}$ :

$$
\mathrm{AB}_{\mathrm{h}}^{*}=\alpha+\beta \mathrm{IA}_{\mathrm{h}}+\gamma \mathrm{FC}_{\mathrm{h}}+\delta \mathrm{PC}_{\mathrm{h}}+\varepsilon_{\mathrm{h}}
$$

If $\mathrm{AB}^{*}{ }_{\mathrm{h}}$ were observed, we would estimate the parameters by OLS. The observed variable $A B_{h}$ is related to the latent $A B^{*}{ }_{h}$ through the observation rule:

$$
A B_{h}=\left\{\begin{array}{cl}
\mathrm{AB}_{\mathrm{h}}^{*} & \text { if } \mathrm{AB}_{\mathrm{h}}^{*}>L \\
L & \text { if } \mathrm{AB}_{\mathrm{h}}^{*} \leq L
\end{array} .\right.
$$

The probability of an observation being censored is

$$
\begin{aligned}
\operatorname{Pr}\left(\mathrm{AB}_{\mathrm{h}}^{*} \leq L\right) & =\operatorname{Pr}\left(\alpha+\beta \mathrm{IA}_{\mathrm{h}}+\gamma \mathrm{FC}_{\mathrm{h}}+\delta \mathrm{PC}_{\mathrm{h}}+\varepsilon_{\mathrm{h}} \leq L\right) \\
& =\Phi\left\{\left(L-\beta \mathrm{IA}_{\mathrm{h}}+\gamma \mathrm{FC}_{\mathrm{h}}+\delta \mathrm{PC}_{\mathrm{h}}\right) / \sigma\right\}
\end{aligned}
$$

where $\Phi(\cdot)$ is the standard normal cumulative distribution function.

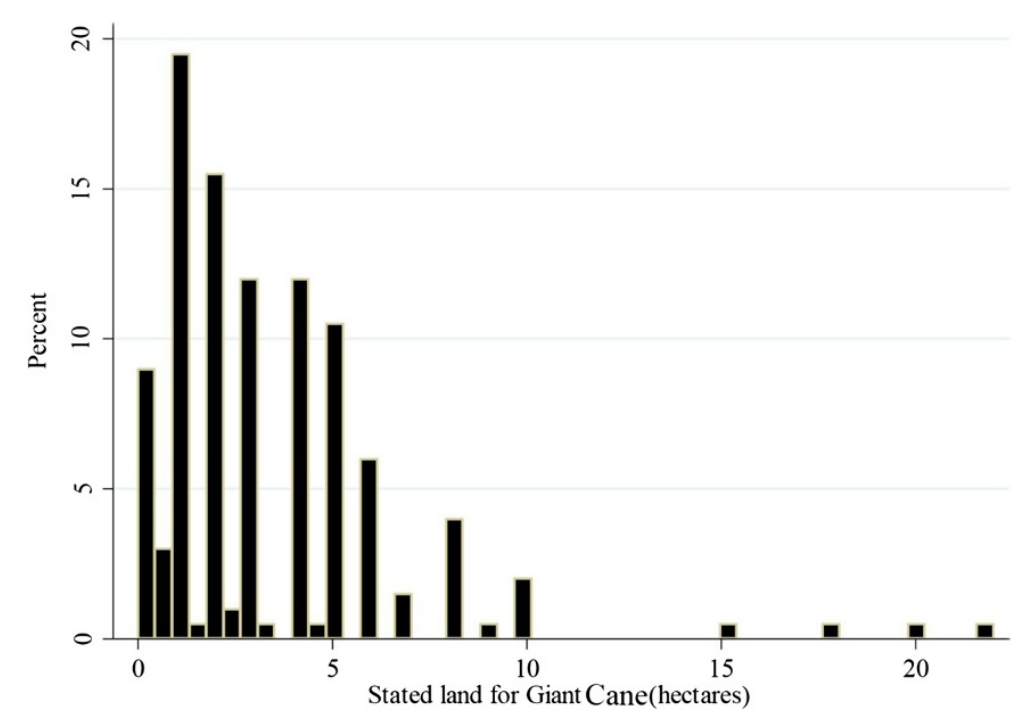

Figure 1 Frequency distribution of stated intention of farmers to allocate some of their land to growing Giant Cane. 


\section{Results and discussion}

In an attempt to condense the set of information collected in the questionnaire section concerning the psychological constructs, a principal component analysis (PCA) was performed. PCA allows original data to be converted into latent constructs (or dimensions). Put differently, dimensions obtained by using PCA represent the main psychological constructs that serve to predict the pro-social (or cooperative) behavior of the sample of farmers interviewed.

The PCA results identified, based on the original 12 variables, five principal components explaining $69.3 \%$ of total variance (Table 4$)$. The first construct $\left(\mathrm{PC}_{1}\right)$ was termed social dilemma. It is characterized by variables that detect a dilemma concerning environmental protection, or the ability to cooperate with other farmers facing environmental issues. The second extracted component $\left(\mathrm{PC}_{2}\right)$ was termed awareness of responsibility. This construct is positively characterized by variables related to personal credence which serve to provide a useful contribution to solutions to environmental issues that entail the production of renewable energy sources. The third construct $\left(\mathrm{PC}_{3}\right)$ was personal norms, based on variables underlining a moral obligation to perform or refrain from specific actions. The fourth component $\left(\mathrm{PC}_{4}\right)$, namely trust in other people's cooperation, comprises variables defining trust in other farmers' willingness to take part in collective action aimed at biomass production. This component is characterized, moreover, by a variable that identifies the trust that a farmer receives from his/her social network when deciding to contribute to environmental protection by producing agro-biomass. Last, but not least, construct $\left(\mathrm{PC}_{5}\right)$, or awareness of consequences, is identified by variables underlining the farmer's consciousness of the positive consequences that his/her pro-social behavior has, or may have, on other members in the area. Once calculated, the PCA scores of the psychological constructs $\left(\mathrm{PC}_{1}, \mathrm{PC}_{2}, \mathrm{PC}_{3}, \mathrm{PC}_{4}, \mathrm{PC}_{5}, \mathrm{PC}_{6}\right)$ are included as predictors of the farmers' intentions to participate in the bioenergy supply chain (Table 5).

Table 6 reports the descriptive statistics of the independent variables selected in the study, while Table 7 shows estimates of the relationship between farmers' intentions to join the bioenergy supply chain and the main driving factors.

Table 5 Components matrix based on NAM variables

\begin{tabular}{lllllll}
\hline Variables & NAM - Psychological constructs & \multicolumn{2}{l}{ Components } \\
\cline { 3 - 7 } & & $\mathbf{P C}_{\mathbf{1}}$ & $\mathbf{P C}_{\mathbf{2}}$ & $\mathbf{P C}_{\mathbf{3}}$ & $\mathbf{P C}_{\mathbf{4}}$ & $\mathbf{P C}_{\mathbf{5}}$ \\
\hline NAM3 & Social dilemma & .840 & -.058 & .085 & -.070 & -.095 \\
NAM2 & & .799 & -.067 & -.049 & -.122 & .062 \\
NAM1 & & .729 & .179 & -.171 & .074 & -.039 \\
NAM6 & Awareness of responsibility & -.086 & .843 & .137 & -.087 & .076 \\
NAM4 & & .212 & .773 & .037 & .174 & -.201 \\
NAM5 & & -.082 & .639 & .097 & .267 & .418 \\
NAM8 & Personal/social norms & -.071 & .111 & .863 & .012 & .108 \\
NAM7 & & -.038 & .104 & .708 & .357 & .076 \\
NAM9 & Trust in other people's cooperation & -.059 & .019 & .060 & .885 & .048 \\
NAM10 & & -.060 & .184 & .388 & .597 & .094 \\
NAM11 & Awareness of consequences & .004 & -.158 & .384 & -.195 & .728 \\
NAM12 & & -.053 & .186 & -.054 & .372 & .717 \\
\hline
\end{tabular}


Table 6 Descriptive statistics of variables included in the empirical model

\begin{tabular}{llllll}
\hline Variable & Description & Mean & Std.dev & Min & Max \\
\hline $\mathrm{AB}$ & Agricultural land to bioenergy (ha) & 3.37 & 3.22 & 0 & 22 \\
$\mathrm{IA}_{1}$ & 1 if male, 0 female & 0.61 & N.A & 0 & 1 \\
$\mid \mathrm{A}_{2}$ & Age (years) & 43.67 & 12.18 & 18 & 80 \\
$\mathrm{IA}_{3}$ & 1 if farmer, 0 entrepreneur & 0.83 & N.A & 0 & 1 \\
$\mid \mathrm{A}_{4}$ & 1 if full-time commitment, 0 part-time & 0.75 & N.A & 0 & 1 \\
$\mid \mathrm{A}_{5}$ & 1 presence of recent investments, 0 otherwise & 0.7 & N.A & 0 & 1 \\
$\mid \mathrm{A}_{6}$ & 1 if crops were changed recently, 0 otherwise & 0.18 & N.A & 0 & 1 \\
$\mid \mathrm{A}_{7}$ & 1 if farmer knows cooperatives, 0 otherwise & 0.59 & N.A & 0 & 1 \\
$\mid \mathrm{A}_{8}$ & 1 if farmer has participated in cooperatives, 0 otherwise & 0.34 & N.A & 0 & 1 \\
$\mathrm{FC}_{1}$ & 1 presence of fallow land, 0 otherwise & 0.34 & N.A & 0 & 1 \\
$\mathrm{FC}_{2}$ & 1 presence of livestock, 0 otherwise & 0.23 & N.A & 0 & 1 \\
$\mathrm{FC}_{3}$ & Total agricultural area & 19.64 & 28.14 & 1.5 & 340 \\
$\mathrm{PC}_{1}$ & Social dilemma & 0 & 1 & -1.44 & 2.66 \\
$\mathrm{PC}_{2}$ & Awareness of responsibility & 0 & 1 & -3.92 & 2.75 \\
$\mathrm{PC}_{3}$ & Personal norms & 0 & 1 & -3.37 & 2.24 \\
$\mathrm{PC}_{4}$ & Trust in other people's cooperation & 0 & 1 & -3.74 & 1.8 \\
$\mathrm{PC}_{5}$ & Awareness of consequences & 0 & 1 & -5.98 & 1.64 \\
\hline & & & & &
\end{tabular}

According to the parameter estimates, those related to psychological constructs $(\delta)$ and farm characteristics $(\gamma)$ significantly affect farmers' propensity to participate in bioenergy supply more than parameters related to farmers' socio-demographic characteristics $(\beta)$. Indeed, among farmers' characteristics, only farmer status (positively) and past knowledge on cooperatives (negatively) affect farmers' willingness to join the bioenergy supply chain. Indeed, two out of three farmers' structural characteristics appear to impact farmers' choice: farms with a larger land endowment are more likely to allocate land to cultivating Giant Reed, while the presence of livestock seems to reduce farmers' propensity to join collective action.

Looking at the role of psychological constructs, four of the five postulated dimensions were found to influence the likelihood of farmers joining collective action. To be precise, our results show that the likelihood of participating in the bioenergy chain increases when the social dilemma dimension decreases. This result confirms what was stated by Ostrom (2000). Specifically, higher suitability of collective action exists for farmers who are willing to cooperate to solve social and environmental dilemmas.

Estimates also indicate higher willingness to join collective action for farmers who consider themselves more useful in providing solutions to environmental issues by producing renewable energy sources (awareness of responsibility dimension). Finally, both farmers' moral obligation to specific pro-social engagement, or personal norms, and farmer's consciousness of the positive consequences of their pro-social behavior (awareness of consequences) seem to affect positively their willingness to participate in collective action.

\section{Conclusions}

The present study aimed to ascertain which determinants most affect farmers' willingness to contribute to common resources management. The empirical study was conducted in an area in the province of Avellino (southern Italy) highly affected by soil 
Table 7 Estimates (in bold estimate of statistically significant parameters)

\begin{tabular}{lllll}
\hline Parameter & Description & Estimates & $\mathbf{t}$ & $\mathbf{P}>\mathbf{t}$ \\
\hline$\beta_{1}$ & Gender & 0.136 & 0.980 & 0.330 \\
$\beta_{2}$ & Age & 0.008 & 1.410 & 0.162 \\
$\boldsymbol{\beta}_{3}$ & Farmer or entrepreneur & $\mathbf{0 . 8 6 7}$ & $\mathbf{4 . 0 4 0}$ & $\mathbf{0 . 0 0 0}$ \\
$\beta_{4}$ & Full-time or part-time commitment & 0.133 & 0.760 & 0.447 \\
$\beta_{5}$ & Presence of fallow land & 0.128 & 0.840 & 0.404 \\
$\beta_{6}$ & Presence of livestock & -0.045 & -0.260 & 0.799 \\
$\boldsymbol{\beta}_{\mathbf{7}}$ & Presence of recent investments & $\mathbf{0 . 5 0 4}$ & $\mathbf{3 . 2 5 0}$ & $\mathbf{0 . 0 0 1}$ \\
$\beta_{8}$ & Crops were changed recently & -0.049 & -0.300 & 0.764 \\
$\gamma_{1}$ & Farmer knows cooperatives & 0.197 & 1.180 & 0.239 \\
$\boldsymbol{\gamma}_{\mathbf{2}}$ & Farmer has participated in cooperatives & $-\mathbf{0 . 2 8 9}$ & $\mathbf{- 1 . 8 8 0}$ & $\mathbf{0 . 0 6 2}$ \\
$\boldsymbol{\gamma}_{\mathbf{3}}$ & Total agricultural area & $\mathbf{0 . 0 1 0}$ & $\mathbf{4 . 3 5 0}$ & $\mathbf{0 . 0 0 0}$ \\
$\boldsymbol{\delta}_{\mathbf{1}}$ & Social dilemma & $-\mathbf{0 . 2 2 1}$ & $\mathbf{- 3 . 0 9 0}$ & $\mathbf{0 . 0 0 2}$ \\
$\boldsymbol{\delta}_{\mathbf{2}}$ & Awareness of responsibility & $\mathbf{0 . 1 4 2}$ & $\mathbf{2 . 0 7 0}$ & $\mathbf{0 . 0 4 0}$ \\
$\boldsymbol{\delta}_{\mathbf{3}}$ & Personal/social norms & $\mathbf{0 . 1 1 4}$ & $\mathbf{1 . 6 6 0}$ & $\mathbf{0 . 0 9 9}$ \\
$\delta_{4}$ & Trust in other people's cooperation & -0.002 & -0.030 & 0.973 \\
$\boldsymbol{\delta}_{\mathbf{5}}$ & Awareness of consequences & $\mathbf{0 . 1 2 8}$ & $\mathbf{1 . 9 9 0}$ & $\mathbf{0 . 0 4 8}$ \\
$\mathbf{a}$ & Intercept & $\mathbf{- 1 . 0 4 4}$ & $\mathbf{- 3 . 0 5 0}$ & $\mathbf{0 . 0 0 3}$ \\
\hline & & & &
\end{tabular}

erosion problems. The study focused on the willingness of farmers to contribute to the public good through biomass production (giant reed). Overall estimates suggest that there is a systematic effect of the farmers' psychological constructs in driving farmers' behavior to be involved in the development of the agro-energy supply chain. The role of these dimensions is at least as important as farms' structural characteristics (land area and farming system). Less significant impact was obtained for farmers' individual characteristics.

The theoretical approach implemented in the paper appears confirmed by the case study results. Common resources management can be achieved when rules regarding the use of public goods are defined by involving stakeholders with strong interdependency (Ostrom, 2010). Social norms help to reduce free-riding by building reciprocity and trust. Moreover, social norms affect the behavior of individuals who are willing to join collective action, with, as a consequence, a sustainable use of public goods. This particularly holds when individuals, in the presence of a social dilemma, operate in the same context and share the same objectives. When such conditions take place, cooperation is initiated. In order to observe the long-lasting success of common resources management, others have to learn to trust the complex network of stakeholders and have to be more willing to adopt reciprocity leading to higher levels of cooperation. Hence it emerges that social dilemma and trust in other people's cooperation represent the most important determinants that affect long-lasting collective action. However, as a result of this study "trust in other people's cooperation" has no significant impact on willingness to participate in collective action to build a bioenergy supply chain. This could be due to the fact that our study concerns an early stage collective action in which interactions are not in place. Put differently, while the trust variable makes sense in the theoretical framework, in this study there are no interactions among actors to be tested. 
Results do not have direct policy or agribusiness implications. However, it captures the existence of conditions able to develop a collective action, through cooperation, aiming at common pool resources management.

Starting from the concept introduced on the basis of this case study, future research could develop in-depth studies in at least two directions. First, the area where data were collected is limited to one region in southern Italy. We believe the area in question is representative of the many Mediterranean areas affected by both low income and environmental issues. However, replication of this study in other areas is necessary to test the external validity of our results. Second, this study tested the participation in collective action on an individual farmer's non-coordinated decision. The results could be different in the case of cooperation induced by external coordination. In this respect, some aspects of collective action, common norms in particular, would be assured by the cooperation and the results could be different. Finally, Ostrom (1990) describes collective action as a dynamic perspective. Future research should take this aspect into account.

Better knowledge of collective action and farmers' propensity to undertake such action could be useful to promote long-term sustainable management of public goods. Therefore the role of political institutions should be to accompany such processes in order to facilitate networking by creating agricultural policies that promote local bioenergy production and sustainable management of public goods with a view to reducing pollution emissions (Kotchen and Moore, 2007) and mitigating soil erosion risk. After all, the call for sustainable development needs to be based on new civic values as well as new forms of participation.

\section{Competing interests}

The authors declare that they have no competing interests.

\section{Authors' contribution}

Authors are equally responsible of every paragraph of the paper. All authors read and approved the final manuscript.

\section{Acknowledgements}

This research received grant from the European Regional Development Fund (PON): "Integrated agro-industrial chains with energy efficiency for the development of eco-compatible processes of energy and bio-chemical production for renewable sources for the land valorization (ENERBIOCHEM)".

\section{Author details}

1Department of Agriculture, AgEcon and Policy Group, University of Naples Federico II, Via Università 96, Portici, NA 80055, Italy. ${ }^{2}$ Department of Agricultural and Forest Sciences, AgEcon and Policy Group, University of Palermo, Viale delle Scienze ed. 4, Palermo 90128, Italy.

Received: 14 July 2014 Accepted: 9 November 2014

Published online: 02 December 2014

References

Agrawal A, Goyal S (2001) Group size and collective action: third party monitoring in common pool resources. Comp Pol Stud 34(1):63-93

Antinori C, Bray DB (2005) Community forest enterprises as entrepreneurial firms: economic and institutional perspectives from Mexico. World Dev 33(9):1529-1543

Berkes F (1987) Common Property Resource Management and Cree Indian Fisheries in Subarctic Canada. In: McCay BJ, Acheson J (eds) The Question of the Commons: The Culture and Ecology of Common resources. University of Arizona Press, Tucson, pp 66-91

Blamey R (1998) Contingent valuation and the activation of environmental norms. Ecol Econ 24:47-72

Caracciolo F, Lombardi P (2012) A new-institutional framework to explore the trade-off between Agriculture, Environment and Landscape. Econ Policy Energy Environ 3:135-154

Dawes RM, Orbell JM, Simmons RT, Van De Kragt AJC (1986) Organizing groups for collective action. Am Polit Sci Rev 80(4):1171-1185

De Groot Jl, Steg L (2009) Morality and prosocial behavior: The role of awareness, responsibility, and norms in the Norm Activation Model. J Soc Psychol 149(4):425-449 
Ebreo A, Vining J, Cristancho S (2003) Responsibility for environmental problems and the consequences of waste reduction: A test of the norm-activation model. J Environ Syst 29(3):219-244

Fujiie M, Hayami Y, Kikuchi M (2005) The conditions of collective action for local commons management: the case of irrigation in the Philippines. Agric Econ 33(2):179-189

Gibson CC, Williams JT, Ostrom E (2005) Local enforcement and better forests. World Dev 33(2):273-284

Guagnano GA (2001) Altruism and market-like behavior: an analysis of willingness to pay for recycled paper products. Popul Environ 22(4):425-438

Guagnano GA, Dietz T, Stern PC (1994) Willingness to pay for public goods: a test of the contribution model. Psychol Sci 5(6):411-415

Guagnano GA, Stern PC, Dietz T (1995) Influences on attitude-behavior relationships: a natural experiment with curbside recycling. Environ Behav 27:699-718

Hisschemöller M, Sioziou I (2013) Boundary organizations for resource mobilization: enhancing citizens' involvement in the Dutch energy transition. Environ Politics 22(5):792-810

Hopper JR, Nielsen JM (1991) Recycling as altruistic behavior. Normative and behavioral strategies to expand participation in a community recycling program. Environ Behav 23:195-220

Joireman JA, Lasane TP, Bennett J, Richards D, Solaimani S (2001) Integrating social value orientation and the consideration of future consequences within the extended norm activation model of proenvironmental behaviour. Br J Soc Psychol 40(1):133-155

Kotchen MJ, Moore MR (2007) Private provision of environmental public goods: Household participation in greenelectricity programs. J Environ Econ Manag 53(1):1-16

Liebe U, Preisendörfer P, Meyerhoff J (2010) To pay or not to pay: Competing theories to explain individuals' willingness to pay for public environmental goods. Environ Behav 43(1):106-130

Liebe U, Preisendörfer P, Meyerhoff J (2011) To Pay or Not to Pay: competing theories to explain Individuals' willingness to Pay for public environmental goods. Environ Behav 43(1):106-130

Meinzen-Dick R, Raju KV, Gulati A (2002) What affects organization and collective action for managing resources? Evidence from canal irrigation systems in India. World Dev 30(4):649-666

Migliore G, Schifani G, Dara Guccione G, Cembalo L (2014) Food Community Networks as Leverage for Social Embeddedness. J Agric Environ Ethics 27(4):549-567, DOl: 10.1007/s10806-013-9476-5, 1-19

Migliore G, Schifani G, Cembalo L (2015) Opening the black box of food quality in the short supply chain: Effects of conventions of quality on consumer choice. Food Qual Prefer 39:141-146

Montada L, Kals E (2000) Political implications of psychological research on ecological justice and proenvironmental behaviour. Int J Psychol 35:168-176

Olson M (1965) The Logic of Collective Action: Public Goods and Theory of Groups. Harvard University Press, Cambridge MA

Ostrom E (1990) Governing the Commons: The Evolution of Institutions for Collective Action. Cambridge University Press, Cambridge, UK

Ostrom E (1991) Governing the Commons. The Evolution of Institutions for Collective Action. Cambridge University Press, Cambridge, MA

Ostrom E (1999) Social capital: a fad or a fundamental concept? In: Dasgupta P, Serageldin I (eds) Social capital: A multifaceted perspective. The World Bank, Washington, DC, pp 172-214

Ostrom E (2000) Collective action and the evolution of social norms. J Econ Perspect 14(3):137-158

Ostrom E (2010) Revising theory in light of experimental findings. J Econ Behav Organ 73:68-72

Ostrom E, Walker J (2003) Trust and Reciprocity: Interdisciplinary Lessons for Experimental Research, Volume VI in the Russell Sage Foundation Series on Trust, Russell Sage Foundation

Pretty J, Ward H (2001) Social capital and the environment. World Dev 29(2):209-227

Rootes C (2012) Climate change, environmental activism and community action in Britain. Soc Altern (Special issue on Community Climate Action) 31(1):24-28

Sayfang G (2010) Community action for sustainable housing: Building a low-carbon future. Energy Policy 38:7624-7633

Schwartz SH (1977) Normative influences on altruism. Adv Exp Soc Psychol 10:221-279

Schwartz SH, Howard JA (1980) Explanations of the moderating effect of responsibility denial on the personal normbehavior relationship. Soc Psychol Q 43:441-446

Schwartz SH, Howard JA (1981) A normative decision-making model of altruism. Altruism and helping behavior, pp 189-211

Stern PC, Dietz T, Abel T, Guagnano GA, Kalof L (1999) A value-belief-norm theory of support for social movements: The case of environmentalism. Human Ecol Rev 6:81-95

Vining J, Ebreo A (1992) Predicting recycling behavior from global and specific environmental attitudes and changes in recycling opportunities. J Appl Soc Psychol 22:1580-1607

doi:10.1186/s40100-014-0018-x

Cite this article as: Cembalo et al:: Bioenergy chain building: a collective action perspective. Agricultural and Food Economics 2014 2:18. 